\title{
IS THERE ANY RELATIONSHIP BETWEEN OXYGEN RESERVE INDEX (ORI) AND ARTERIAL PARTIAL PRESSURE OF OXYGEN? A PRELIMINAR STUDY IN SURGICAL PATIENTS.
}

\author{
Duca A', Del Rio E', Fuentes I', Incertis R', Llau JV', Ferrandis R². \\ 'H. Clínic de València, ${ }^{2} \mathrm{H}$. La Fe de València (Spain)
}

\section{BACKGROUND AND AIM OF THE STUDY}

The oxyhemoglobin dissociation curve characterizes the relationship between arterial oxygen saturation $\left(\mathrm{SaO}_{2}\right)$ and partial pressure of oxygen $\left.(\mathrm{PaO})_{2}\right)$. But once haemoglobin is fully saturated pulse oxymetry cannot assess oxygen partial pressure. Recently a new continuous-non-invasive measurement of arterial blood oxygen has been developed. The Oxygen Reserve Index (ORI) is not a measure of $\mathrm{PaO}_{2}$, but a non-dimensional index ranging between 1.0 (high reserve of oxygen) and 0.0 (no oxygen reserve). It has been proposed that the measurement of ORI could add some information to $\mathrm{SaO}_{2}$ in order to anticipate a desaturation or to assess a hyperoxic situation.

The objective of this preliminary study is to assess if there is any relationship between $\mathrm{ORI}$ and $\mathrm{PaO}_{2}$, since there are other parameters that could affect it (eg.: $\mathrm{CO}_{2}$ or temperature)
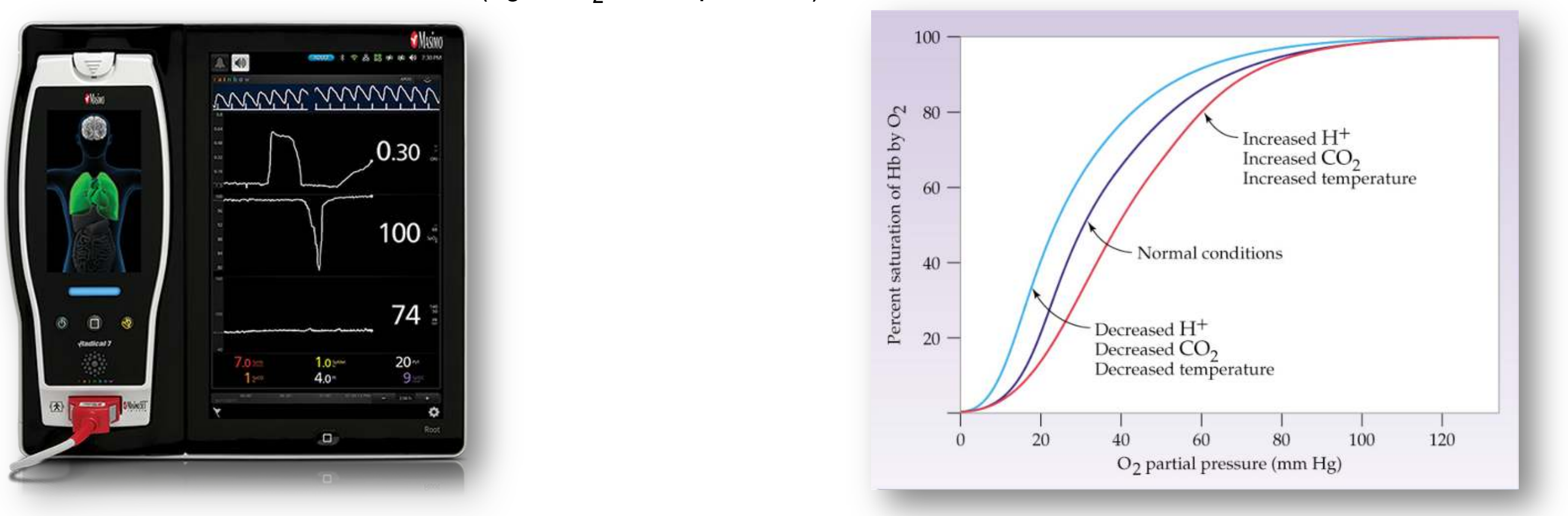

\section{METHODS}

This study included patients with an arterial line (cannulated as current practice). They were monitored with the co-oxymetry monitor Radical7 (Masimo®, Irvine, CA). During the perioperative period we only took the samples we needed to monitor from the gasometry results, and at that moment they were compared with the ORI values. To search the correlation between $\mathrm{ORI}$ and $\mathrm{PaO}_{2}$, a regression analysis was performed $\left(r^{2}\right)$ using Microsoft Excel $2011 \AA$ (Microsoft Corporation). As this study is a purely descriptive one and no comparator has been used, no other statistical analysis was considered necessary.

\section{RESULTS}

$28 \mathrm{ORI}$ values and $\mathrm{PaO}_{2}$ measurements were obtained from intraoperative data collection in 13 patients (7M-6F, 2 ASA IV-8 ASA III-3 ASA II). All patients had $\mathrm{SaO}_{2} \geq 97 \%$ at the moment of the data collecting. Range of $\mathrm{PaO}_{2}$ values was $144-259 \mathrm{mmHg}$; range of ORI values was $0,17-1,00$. Regression study showed that there was no good global ORI- $\mathrm{PaO}_{2}$ ratio $\left(r^{2}=0,17637\right)$ (Fig 1). Although it was higher if we consider only $\mathrm{PaO}_{2}$ values $<200 \mathrm{mmHg}(\mathrm{n}=18)$ $\left(r^{2}=0,31967, \mathrm{PaO}_{2}\right.$ range 144-195, ORI range 0,17-0,89) (Fig 2), it does not reach a suitable correlation. Individual results did not show that high values of ORI (even >0.75) suggested necessarily a hyperoxic state.

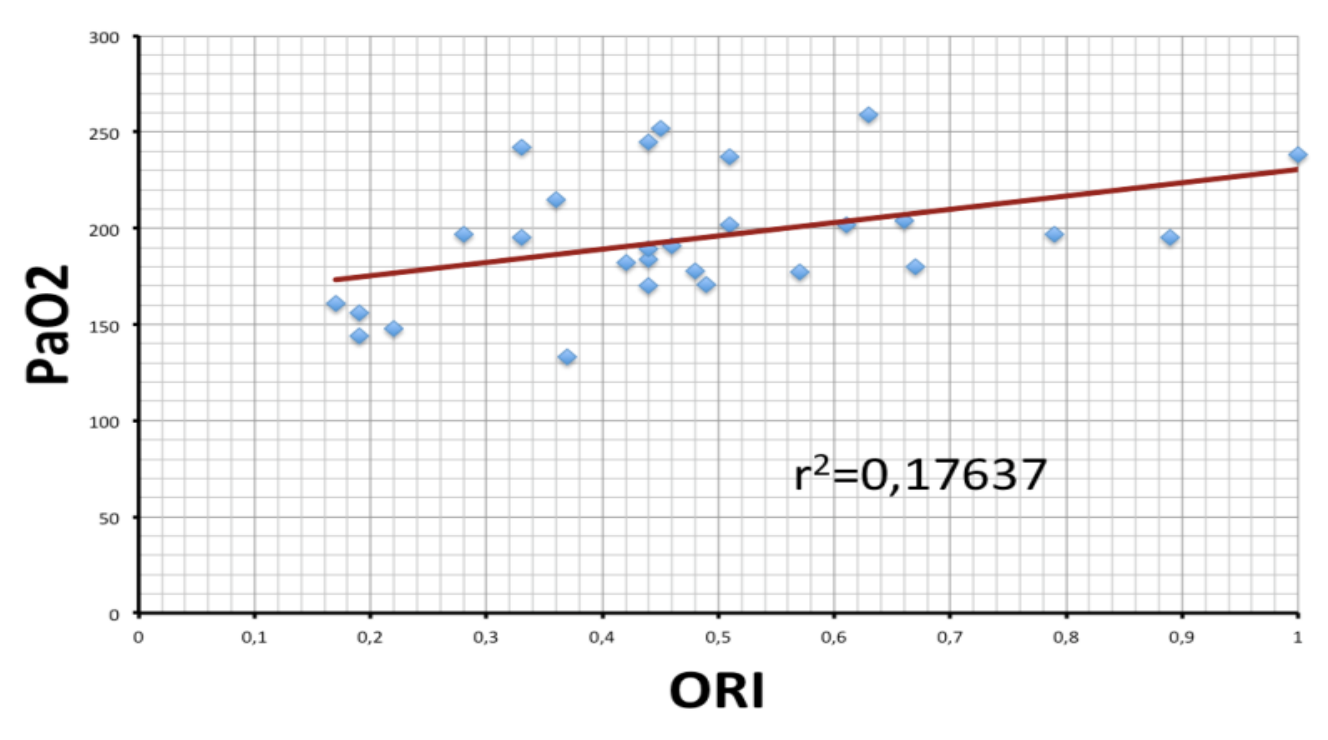

Fig 1. Global ORI-PaO2 correlation.

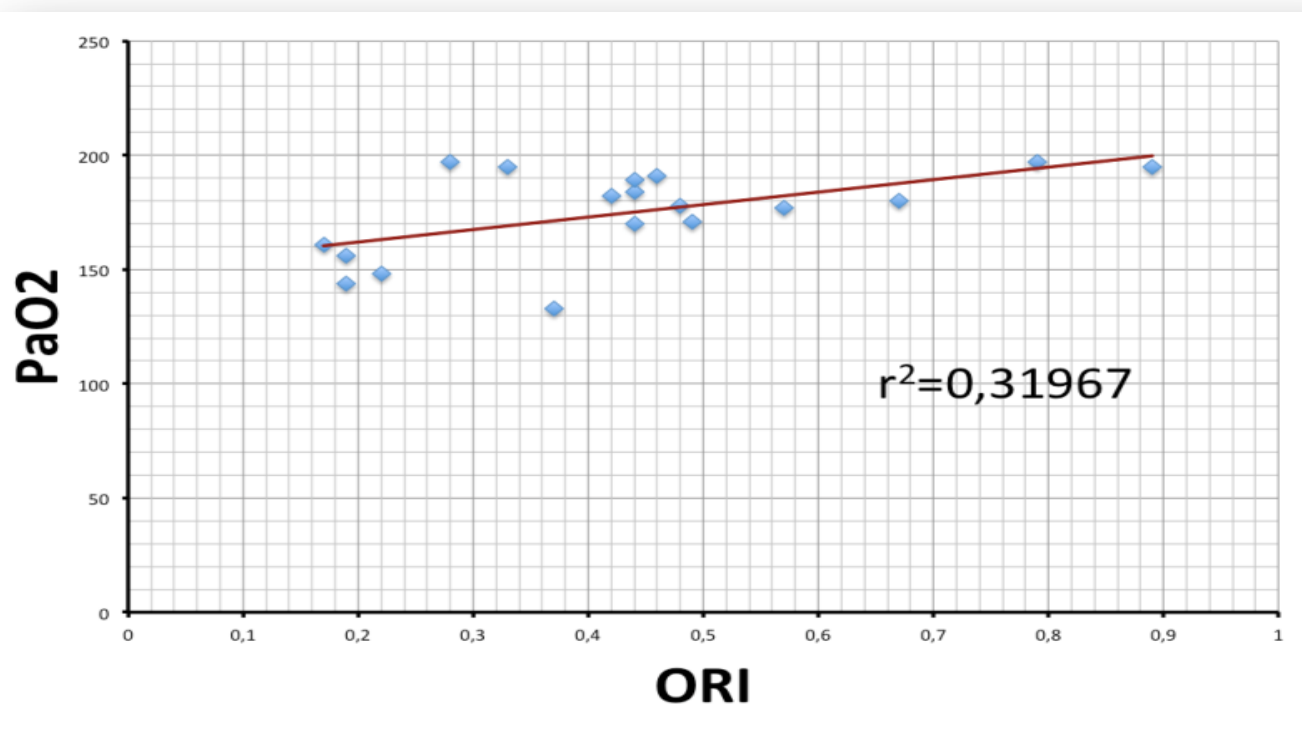

Fig 2. ORI-PaO2 correlation only for PaO2 $<200 \mathrm{mmHg}$

\section{CONCLUSIONS}

These results suggest that continuous monitoring of ORI could be useful to anticipate the decrease of the estimated oxygen reserve for $\mathrm{PaO}_{2}$ higher than $100 \mathrm{mmHg}$. The correlation between $\mathrm{ORI}$ and $\mathrm{PaO}_{2}$ values is not suitable, although more studies are needed to fully assess its

usefulness during the perioperative period. 